\title{
Material and field impacts on cement compositions
}

\author{
Aleksandr Rubanov ${ }^{1, *}$, Nikolay Gorlenko ${ }^{1}$, and Vladimir Vergasov ${ }^{1}$ \\ ${ }^{1}$ Tomsk State University of Architecture and Building, 634003 Tomsk, Russia
}

\begin{abstract}
The paper studies the effect of combined field impact on cement compositions. The priority research direction involves creation of cement compositions and technologies that meet the requirements of technological availability and efficiency, environmental safety and sustainability, biocompatibility, economic efficacy and energy and resource saving. The paper proves that these criteria can be affected by material and field impacts on cement systems, which leads to considerable increase in strength of hardened cement paste, mortars and concretes. With this purpose, the paper presents detailed study on combined impact of ultrasound and magnetic field on grouting fluid of cement systems and strength of hardening systems in normal conditions. Compressive strength of cement and sand mortar was found to increase on average by $30-45 \%$.
\end{abstract}

\section{Introduction}

Development of new cement types, modifying chemical admixtures, external impacts on cement systems enhance the ability to control physico-mechanical and operational characteristics of such systems, both on the stages of cement and water interaction and ultimate strength formation in a system [1-3].

According to the universal framework of environmental studies and modern building materials science, all newly obtained materials, including those based on cement systems, must meet the criteria previously formulated in [4-5].

Among all cement system components, grouting fluid still remains the most available one for direct modification of hardened cement paste properties [6-10]. However, if we take water, in spite of remarkable success in this field, its modification by physical and chemical impacts meets the above mentioned criteria to a greater extent, especially when combined methods of material and field impacts are applied [3].

This study is aimed at increasing strength of cement and sand mortar by affecting the grouting fluid by ultrasound with given frequency and by static magnetic field with given intensity.

To date, no previous studies have been performed on the topic of combined impact on cement systems grouting fluid.

\footnotetext{
* Corresponding author: rubal06@yandex.ru
} 


\section{Materials and methods}

When performing the study, USU-0707 ultrasound machine with the acoustic frequency of $125 \pm 6 \mathrm{kHz}$ and power demand of $9 \mathrm{~W}$ was used. Static magnetic field was produced by a system of NdFeB magnets with the magnetic field strength of $0.10 \pm 0.02$ Tesla on the magnet surface. System of magnets created areas with magnetic field gradients, through which distilled water was put at the velocity of $0.7 \mathrm{~m} / \mathrm{s}$. Grouting fluid was affected in cycles in a closed-loop system. Different variants of combined impact were applied, including separate and successive exposure to ultrasound and magnetic field, as well as simultaneous and combined impact of these material-field modifiers.

The impact types were chosen based on multidirectionality of their effect on water and electrolyte water solutions.

Changes in physico-chemical properties of water and cement compositions were studied with the help of LAMBDA 265 UV-spectrophotometer and SDTQ 600 thermal analyzer.

To define compressive strength cubic specimens sized $(70,7 \times 70,7 \times 70,7) \times 10^{-3} \mathrm{~m}$ were made from cement and sand mortar composed of 1 part of M400 Portland cement and 3 parts of sand, with water to cement ration of 0.45 . The specimens mixed with activator liquid and distilled water were cured in a moist chamber and tested for compressive strength within given periods according to the standard methods (GOST 5802-86) [13].

The number of specimens in each series of compressive strength tests was no less than 6 . All obtained test results were statistically analyzed.

\section{Results and discussion}

Exposure of both distilled and natural water to static magnetic field results caused shift of $\mathrm{pH}$ medium towards the alkaline one up to the values of 8.5-9.0 compared to the corresponding values in test water $(\mathrm{pH}=6.86)$. At the same time, $\mathrm{UV}$ spectroscopy analysis showed that density of hydrogen bonds under cyclic magnetic treatment increases by $25-$ $50 \%$ depending on the number of cycles (Fig.1).

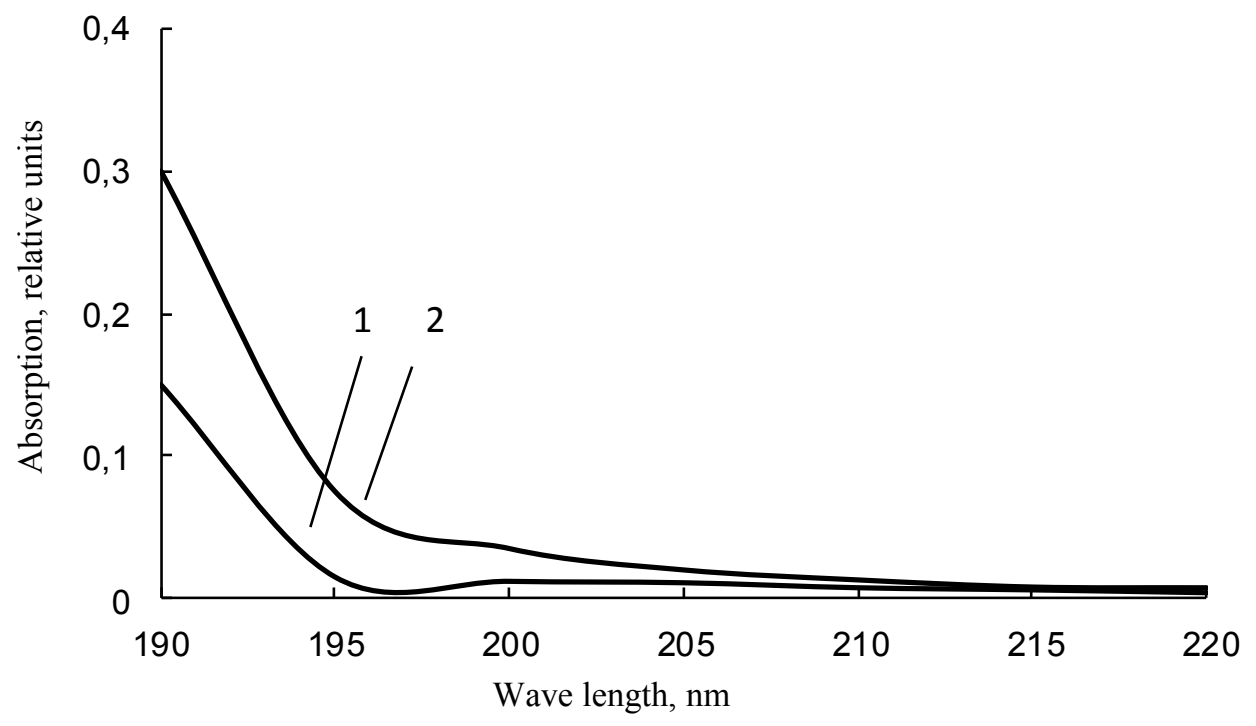

Fig. 1. UV-absorption spectra in distilled water: 1 - test specimen; 2 - after magnetic field treatment. 
Mixing of hardened cement paste with such water ensures higher bond density between water molecules and Portland cement clinker, which is confirmed by comparison of thermograms of hardened cement paste in the studied test specimens of the same age [9]. Shift of endo effects of water dehydration towards higher temperature values (by $20-30 \%$ ) confirms the previously made assumptions [11].

Treatment of water with ultrasound of various energy and with various exposure time results in dispersion of large water clusters into smaller fragments and, as a consequence, leads to increase of its electrical conductivity and hydrogen ions concentration in liquid phase. Based on this, a conclusion can be drawn that the cement-water system must be very sensitive to succession of combined impact methods application for water as grouting fluid for cement systems.

The results of compressive strength tests on cement and sand mortar specimens under various impacts are given in Table 1.

Table 1. Strength of cement and sand mortar.

\begin{tabular}{|c|c|c|c|c|}
\hline \multirow{3}{*}{ No. } & \multirow{3}{*}{ Type of impact } & \multirow{3}{*}{$\begin{array}{l}\text { Time and mode of } \\
\text { impact on grouting } \\
\text { fluid, min }\end{array}$} & \multicolumn{2}{|c|}{ Hardening time, days } \\
\hline & & & 3 & 28 \\
\hline & & & \multicolumn{2}{|c|}{ Specimens strength, $\mathrm{MPa}$} \\
\hline 1 & Without treatment & - & $3.4 \pm 0.2$ & $14.9 \pm 0.2$ \\
\hline \multirow{4}{*}{2} & \multirow{4}{*}{ Ultrasound (US) } & 15 & $7.9 \pm 0.4$ & $18.4 \pm 0.2$ \\
\hline & & 30 & $6.1 \pm 0.3$ & $20.3 \pm 0.4$ \\
\hline & & 45 & $7.8 \pm 0.4$ & $19.1 \pm 0.3$ \\
\hline & & 60 & $6.7 \pm 0.3$ & $20.1 \pm 0.4$ \\
\hline 3 & Magnetic field (MF) & 7 cycles & $6.6 \pm 0.3$ & $18.6 \pm 0.3$ \\
\hline 4 & $\begin{array}{l}\text { Successive impact by } \\
\text { US+MF }\end{array}$ & $\begin{array}{l}30 \text { minutes }+7 \\
\text { cycles }\end{array}$ & $7.2 \pm 0.3$ & $21,6 \pm 0,4$ \\
\hline 5 & $\begin{array}{l}\text { Successive impact by } \\
\text { MF+US }\end{array}$ & $\begin{array}{l}7 \text { cycles }+30 \\
\text { minutes }\end{array}$ & $6.2 \pm 0.2$ & $16.7 \pm 0.2$ \\
\hline 6 & $\begin{array}{c}\text { Simultaneous impact y US } \\
\text { and MF }\end{array}$ & 30 & $5.8 \pm 0.2$ & $15.4 \pm 0.2$ \\
\hline
\end{tabular}

As can be seen from the Table 1, strength value of hardening structures in cement-water system after impact by only ultrasound at the age of 28 days varies between 18.4 and 20.3 $\mathrm{MPa}$ depending on the exposure time, which is $23-35 \%$ higher than that in test specimens.

After impact by static magnetic field only the strength of specimens increased by $25 \%$ at the same age. When combined impact of ultrasound + magnetic field was applied to specimens, their compressive strength increased by $45 \%$, and after impact by magnetic field + ultrasound - by $12 \%$.

Test results analysis shows that succession of impact leads to different strength parameters of cement and sand mortar. According to the authors' opinion, it can be caused by the reasons as follows. Under initial ultrasound impact, dispersion of water medium comes with formation of various short-lived particles and states in water, cavitation effects and other related phenomena which become sensitive to magnetic field impact. As a result, water reactive capacity rapidly increases in relation to cement and leads to increase in strength parameters. Under magnetic field impact followed by ultrasound impact, the latter appears less effective for the same values of energy and exposure time, due to formation of 
stronger structures of liquid phase clusters. As a consequence, lower strength values are observed (compared to those obtained for impact type No.4, Table 1), which are still higher than those in test specimens.

At the same time, under simultaneous impact by ultrasound and magnetic field, the strength values of hardening structures fluctuate and come with interchange of increase and decrease of strength in a cement system.

Additional tests showed that the water subjected to a certain type of impact retains its maximum reactive capacity in relation to cement within first 4 hours. However, even 7 days after water treatment, the impact effectiveness is still high, and the strength of hardening structures is higher than that of test specimens [9].

\section{Conclusion}

The performed study showed that the suggested method of grouting fluid successive treatment first with ultrasound and then with magnetic field can be recommended for production of cement-based building materials.

Further investigations in this field will be aimed at increasing efficiency of the studied technologies for cement systems hardening not only in normal conditions, but also in extreme ones. The examples of fields for further studies can be the following: hardening at negative temperatures due to complex modification of grouting fluid with antifreeze admixtures [12] which are widely used in cold weather concreting of precast structures.

\section{References}

1. S.V. Samchenko, Formirovanie i genezis struktury cementnogo kamnja [Formation and genesis of the structure of hardened cement paste] (MISI - MGSU Publishing House, Moscow, 2016) (in Russian)

2. Y.M. Bazhenov, Modificirovannye vysokokachestvennye betony [Modified High Performance Concrete] (Association of Civil Engineering Universities, Moscow, 2006) (in Russian)

3. Y.S. Sarkisov, News of Higher Educational Institutions. Construction 2, 106-109 (1993) (in Russian)

4. Y.S. Sarkisov, N.P. Gorlenko, I.A. Rakhmanova, Polzunovsky vestnik 3, 168-171 (2016) (in Russian)

5. N.O. Kopanitsa, V.N. Safronov, O.V. Demyanenko, A.A. Shpilekova, Efficient techniques and technologies in building materials science, Proceedings of Scientific Conference (Novosibirsk, February 14-17, 2017) (in Russian)

6. J.C. Smith, F. Merzel, C.S. Verma, S. Fischer, J. Mol. Liq. 101, 27-33 (2002)

7. T. H. Plumridge and R. D. Waigh, J. Pharm. Pharmacol. 54, 1155-1179 (2002)

8. C. H. Cho, J. Urquidi, S. Singh, S. C. Park, G. W. Robinson, J. Phys. Chem. A 106, 7557-7561 (2002)

9. N.P. Gorlenko, Y.S. Sarkisov, Nizkojenergeticheskaja aktivacija dispersnyh sistem [Low-energy activation of dispersion systems] (TSUAB Publishing, Tomsk, 2011) (in Russian)

10. A.N. Gul'kov, Y.A. Zaslavsky, P.P. Stupachenko, Primenenie magnitnoj obrabotki vody na predprijatijah Dal'nego Vostoka [Application of magnetic water treatment at industrial enterprises of the Far East] (Far East University Publishing, Vladivostok, 1990) (in Russian)

11. Y.S. Sarkisov, N.P. Gorlenko, V.N. Safronov, S.A. Kugaevskaya, M.A. Kovaleva, T.A.Ermilova, D.A. Afanasyeva, Vestnik of Tomsk State University. Chemistry 2, 20 
29 (2015) (in Russian)

12. A.V. Lagojda, N.A. Romanova, O.S. Ivanova, O.E. Koroleva, Rukovodstvo po primeneniju betona s kompleksnymi protivomoroznymi dobavkami [Handbook on the use of concrete with complex antifreeze admixtures] (Publishing house of Reinforced Concrete Research Institute, Moscow, 1987) (in Russian)

13. GOST 5802-86. Mortars. Test methods, 16 (Standartinform, Moscow, 2010) (in Russian) 